\title{
Exploring the need of using Auto-Produced e-Learning Objects (Generator) in Oman Schools
}

\author{
Authors \\ Dr. Nader Shemy ${ }^{*}$, Dr. Walid Aboraya ${ }^{\dagger}$, Dr. Sameh Said ${ }^{\ddagger}$, Dr. Muna Alkalbani ${ }^{\S}$, Naglaa Shehata**, \\ Baraa Abdelhady ${ }^{\dagger \dagger}$
}

\section{Abstract}

The research aims to investigate the needs of Omani teachers to use a learning objects generator for the purpose of designing auto produced e-learning objects. Those objects are meant to be designed by users who do not have specialized knowledge and skills in the design and production processes. The platform is based on the idea of "Wizard" which allows any user to design and produce e-learning objects in less time and effort. Based on a thorough review and analysis of relevant regional and global experiences, the development of the platform will be guided by the international technical and educational standards in this field after adapting them to the needs and requirements of the Omani and Arab education community. To achieve the study aim, a questionnaire was developed by the researchers and distributed to a group of fifty Omani teachers to know their opinion about the need for using a learning objects generator if made available for the post-basic education stage. The results shows that most teachers $(88.93 \%$, Mean $=4.35)$ agree to establish a learning objects generator. Finally, the study suggested a model for developing the learning objects generator to be used by teachers in Omani schools.

Keywords: e-Learning, e-Content, e-Learning Objects, Oman Educational Community.

\footnotetext{
${ }^{*}$ Main Researcher, Arab Open University, Oman

+ Arab Open University, Oman

‡ Sultan Qaboos University, Oman

${ }^{\S}$ Ministry of Education, Oman

** Helwan University, Egypt

${ }^{+\dagger}$ Dar Al-Fatwa, Egypt
} 


\section{Introduction}

Learning objects are a form of e-content, they can be defined as digital learning resources that can be reused to achieve different learning outcomes, as each teacher can use them according to the requirements of the educational situation. Generally, they enrich the educational environment and contribute to achieving the targeted educational goals. That is why it is good to find a way that encourages teachers to produce learning objects by themselves. However, teachers do not have the enough time or skills to produce quality learning objects that are consistent with the educational and technical standards. Thus, providing teachers with an elearning generator to guide them in creating their learning objects in an easy and professional way is required.

Learning objects generator can help teachers to create shareable educational resources without possessing specialized technical and pedagogical skills. Such objects can be used as an entity to achieve specific learning goal or can be combined to form a complete course.

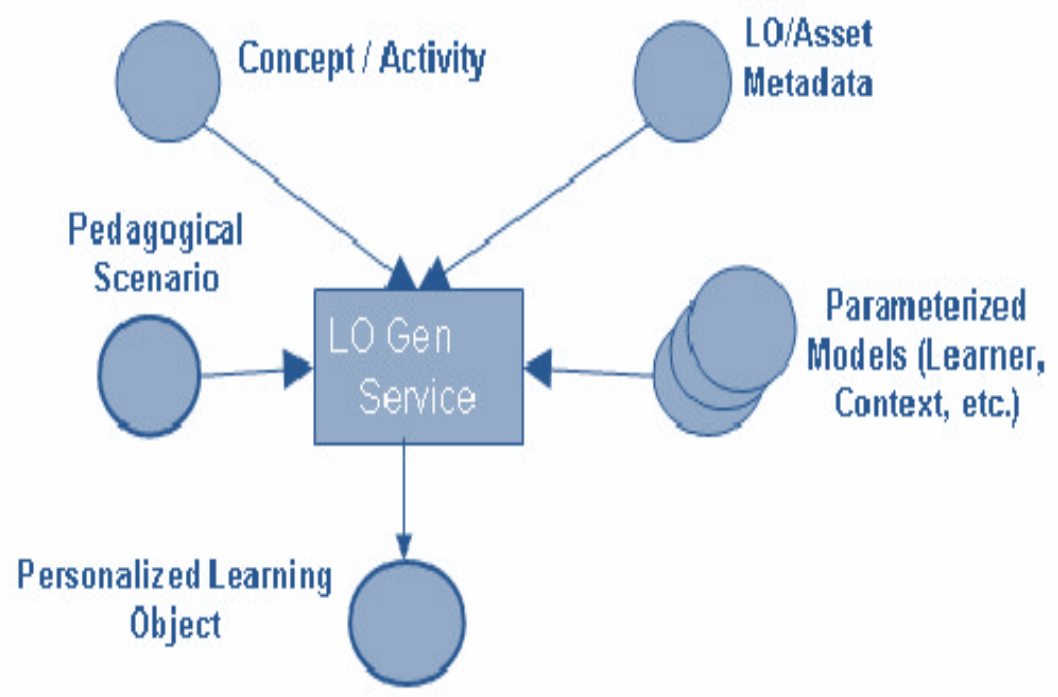

Figure 1 Inputs/Outputs of the LO Generator (Staikopoulos et al., 2014)

The LO Generator in figure 1 uses number of different models to both select and generate these personalized learning objects. In order to aid the personalized selection process, the LO Generator makes use of the learner model to obtain information about the general preferences and also the pedagogical preferences of the learner.

Similar information which may be of use to the service is information about the teacher, including their preferred pedagogical strategy, or specific details they may want to be included in the course. Use will also be made of information obtained from the repository of contextual data, which stores information about the environment, device type, etc. For example, it would be very important to know what type of device the learner will be looking at the course on, because a LO that would be suitable for viewing on a full-size screen would be very different to a LO that would be suitable for viewing on a PDA screen. A narrative is also included and executed within the adaptive engine. This narrative provides the storyline 
or strategy which will be used to enable the selection or creation of the relevant learning objects. (Poultsakis et al., 2021), (Onofrei \& Ferry, 2020)

The researchers believe that learning objects should be designed and developed to be consistent with the nature of the educational content of the subjects at that educational stage, in order to achieve the intended learning outcomes for each of those subjects, and to emphasize that these objects reflect the concept of interaction between the student and the content, by providing content in a different style. For the traditional accepted style, where the content presentation style encourages all students to interact with it through processes of analysis, interpretation, and extraction of targeted knowledge, with the provision of activities and exercises that complement the learning process, and there is a wide scope for selfevaluation of each student's learning level after completing the learning of each object.

The researchers emphasize the need for having a mechanism to collect these objects in one place, this place allows any student or teacher to access the target learning object according to his learning / educational needs, so the researchers see that the concept of digital platforms ePlatform is the most appropriate place in this regard.

The problem that many teachers face in their design of electronic educational content, as this design requires special knowledge and skills in dealing with educational content in terms of educational design and technical design, unlike the technical side, this matter represents a hindrance to any attempt by teachers towards the production of educational electronic content of high quality. An added value, and from here it was necessary to develop an educational and technical solution that overcomes this obstacle and provides a high-quality exit that achieves the target and the desired level of the class of teachers in all educational stages without there being any special requirements on the educational and technical side of teachers.

Therefore, this research project seeks to develop an Omani platform to make digital knowledge available, which allows learners, interested persons and other stakeholders to design and produce electronic learning objects on their own without any educational or technical requirements or needs, only the teacher introduces the specialized educational content in it, including what it contains activities, evaluations, or auxiliary media for that platform in light of a specific mechanism, so that at the end of the matter and during a very limited time and without any effort that may represent a burden on the user, he will eventually obtain a learning object on its own. It is available to all registered users of the platform, and the teacher can exploit this object for any other purposes and in any other educational context.

\section{Literature}

\subsection{Concept of Learning Objects}

There are many definitions of learning objects, and each person defines them according to how s/he use them. Nowadays they are known as "Reusable Learning Objects". This term dates from the late twentieth century and refers to components that can be transferred and reused in educational lessons in a digital format and then used again as part of the educational process. Reusability eliminates the need to create new objects each time, lowering costs and increasing productivity. (Ho, 2021), (Mourão \& Netto, 2019) 
A learning object, according to the International Society for Technology in Education (ISTE), is any digital or non-digital object that supports the learning process and can be customized to the needs of a group of learners and reused in other learning situations. Also, it can define them as "digital learning units that contain small particles of educational content prepared in a digital form, address a specific goal, and can be reused in another educational situation. And they must adhere to digital content design quality standards in their production. (Martínez, 2021), (Goranova, 2019)

In our opinion, a learning object is an increased integration and use of multimedia by the learners that allows them to reuse it in the appropriate educational situation and achieve the desired learning outcomes.

In this context, the most common terms related to learning objects and used in the educational field can be demonstrated as follows: (Huba, Hypiusová \& Tapák, 2019), (Carvalho et al., 2020)

- Step: It refers to the smallest integrated educational entity that includes all components of the learning process.

- Lesson: It refers to an entity that includes more than one step and considers the increase in the number of activities, assessments, and other components of the learning process in proportion to the number of steps used.

- Path: It refers to the entity that includes more than Lessons, which is the closest thing to an integrated educational unit that is similar to the Modules, considering the presence of an intense dose of interactions between content, learners, activities, assessments, and the diversity in the media used.

- SIM: It is an abbreviation for the term simulation, meaning simulation, and this style is concerned with displaying content in the form of interactive simulation clips, such as laboratory experiments.

\subsection{The importance and advantages of digital learning objects}

According to many studies and literature, learning objects play a significant role in the teaching and learning processes; for students, it provides privacy in the sense that it allows them to tailor curricula to their specific needs and assist them in learning, a process known as individualization of education, so that the students' learning resources vary by navigating in online repositories and websites, and they can access different topics through these learning objects.

The importance of learning objects is highlighted in the possibility of their participation and use in more than one environment and from more than one teacher, as mentioned by Hale \& Weaver (2021). They also help teachers develop their teaching methods, attract students' attention, enhance their learning, and help some students overcome their weaknesses, according to Kay \& Knaack (2008).

When it comes to the benefits of learning objects, studies, and literature show that they are numerous and varied. According to Choez et al. (2021), learning objects assist educational institutions in transferring a set of experiences that they provide to learners, as well as 
assisting learners in performing the tasks assigned to them during the educational situation. They allow them to progress in their education at their own pace, based on their abilities. They also enable students to search for specific units and obtain the information they require. And work to improve the efficiency of learning and diversify the sources of information in order to make it more flexible in terms of content and mastery of scientific concepts.

Learning objects, on the other hand, can be easily deployed in learning content management environments and help provide practice and training in the learning environment, as well as improve self-learning and distance learning skills. Also, digital learning objects have number of advantages, according to Martinez et al. (2021), including providing learning experiences for learners and their interaction with learning content, allowing the institution to achieve its educational goals, saving costs, and providing different alternatives to users of those alternatives, and contributing to the development of innovative thinking.

Silvia (2015) presents a set of advantages that distinguish learning objects when they are used in the context of the teaching and learning process, and the most important of these advantages are: (1) flexibility, as the student is allowed to stop reviewing the content of the learning object whenever he wants, according to his speed in assimilating information, and then resume reviewing it again. (2) Repetition, where the student is allowed to repeat the presentation of each slide contained in the learning object more than once, in order to understand its content well. (3) Access, whereby the student is given access to the learning objects wherever they are, as they are made available through the Internet. (4) Comprehensiveness, as each educational object includes all components of learning (content, evaluation, activities, ...) (5) relevance, as the scientific content is precisely defined in order to reflect the intended educational goal. (6) Motivation, as the small scientific content provided through the learning objects helps to increase the motivation of learners towards learning, in addition to the attractions they provide. (7) Facilitating competency-based learning. (8) Added value: where learning organisms provide an added value over the scientific content in its traditional form. Robson adds other advantages to the use of learning objects, the most important of which are: (9) Update, as it is easy to update information or design any educational element, due to the small size of the information it contains, and therefore does not require much effort or a long time. (10) Accuracy of design, as many instructional design models are available that suit the nature of the learning elements, and therefore their designers do not find any obstacle to their design with accuracy and efficiency. (11) Compliance with SCORM standards: Thus, learning elements can be made available through any learning and content management system, which means greater spread and wider use (Choez et al., 2021), (Basuhail, 2020), (Rutkauskiene et al., 2019).

\subsection{Learning objects in educational institutions in Oman}

The Sultanate of Oman's Department of Electronic Content makes great efforts to provide the educational community with a variety of learning objects produced by those in charge of production. On the other hand, the department intends to put forth more effort in its annual plans by holding training sessions led by educational program developers. Both theoretical and practical aspects are covered in these courses. Despite these efforts, the ministry of education has not yet achieved the level of production and distribution of digital educational units that some Arab and foreign countries have.

Some teachers may create instructional pieces based on their basic abilities, but without 
regard for quality standards in production, which represent educational and technical requirements. Here is where we need to take a step back and consider our current reality of effectively using instruction objects in the classroom, as well as the challenges we face in designing and producing independent learning objects.

In the same vein, outside of the Ministry of Education's purview, the SAS center of the Ministry of Technology and Communications is working to create instructional pieces that fit the curriculum's lessons and that the teacher can reuse in new learning situations.

\subsection{Obstacles to employing learning objects in the Sultanate of Oman}

Obstacles to using learning objects in the educational process that the Omani community faces can be divided into two categories: obstacles relating to teachers and obstacles relating to entities responsible for using learning objects in the educational process.

First, obstacles relating to teachers:

- Teachers' and trainees' concerns about using electronic learning media in the classroom, as well as their fear of undervaluing their primary role, which is teaching, and moving into the field of production as specialists.

- One of the barriers to using learning objects is language, as some authoring programs are in English, and the programming process necessitates the use of specialists.

- A lack of understanding of fundamental computer and Internet skills.

- A shortage of experience designing high-quality educational software.

Second, obstacles relating to entities responsible for using LOs in the educational process:

- A limited infrastructure, as evidenced by the inability to meet the necessary financial, equipment, and service requirements to produce learning objects.

- A lack of incentives for teachers to be creative in the production field.

- There are no decisions that necessitate the use of digital learning units in order to improve learning.

- A low-efficiency hardware for producing software, as some authoring programs require specific programs.

- The lack of a dedicated studio for the production team, which would allow them to collaborate on instructional parts as a team.

The researchers see the urgent need for an easy-to-use mechanism in the design and production of electronic content by teachers themselves in a manner that does not conflict with their capabilities, knowledge and limited skills in this field, and the need for an electronic space that accommodates what is designed and produced by teachers and makes it available to students without any restrictions or conditions, provided that it is what is designed and produced is in line with the educational, psychological and behavioral needs and requirements of students, which prompted researchers to uncover the role of a digital platform that contains electronic learning objects in facilitating the task of designing and producing these objects on their own through the teachers themselves, and then making them available on the same platform for the beneficiary students.

\section{Methodology}




\subsection{Participants}

The current study used a descriptive approach to investigate Omani teachers' need to have learning objects generator to help them easily produce digital learning materials linked to the curriculum they are teaching. To do so, fifty teachers were randomly chosen from 5 schools in Muscat.

\subsection{Research tool}

The researchers created a questionnaire to gather data from teachers regarding their opinion to have a learning objects generator to help them create digital content. The questionnaire was designed using five-point Likert scale. To test the questionnaire's validity, experts in the field were consulted. The questionnaire was piloted on 5 teachers with varied years of experience to ensure its validity. The Cronbach alpha coefficient of the scale was found to be $(0.86)$, indicating that it is reliable.

\section{Results and discussion}

A questionnaire was conducted for a random sample of fifty teachers in the post-basic education stage to measure the need for having learning objects generator from the teachers' point of view.

Table 1 Questionnaire for teacher about Digital knowledge generator 


\begin{tabular}{|l|c|c|c|c|c|c|c|}
\hline \multicolumn{1}{|c}{ 1-Strongly Disagree 2- Disagree } & \multicolumn{1}{c}{ 3-Neutral } & \multicolumn{3}{c|}{ 4- Agree } & 5- Strongly Agree \\
\hline \multicolumn{1}{|c|}{ Statemt } & SD & D & N & A & SA & Mean & STDV \\
\hline $\begin{array}{l}\text { The generator will allow teachers to produce } \\
\text { learning objects without the need to have } \\
\text { technical skills. }\end{array}$ & $1 \%$ & $1 \%$ & $3 \%$ & $76 \%$ & $19 \%$ & 4.66 & 0.72 \\
\hline $\begin{array}{l}\text { The generator will allow to produce different } \\
\text { styles of learning objects to meet the students } \\
\text { needs. }\end{array}$ & $6 \%$ & $2 \%$ & $7 \%$ & $61 \%$ & $24 \%$ & 4.27 & 1.14 \\
\hline $\begin{array}{l}\text { The generator will allow to produce learning } \\
\text { objects addressing the curriculum. }\end{array}$ & $3 \%$ & $1 \%$ & $8 \%$ & $65 \%$ & $23 \%$ & 4.46 & 0.93 \\
\hline $\begin{array}{l}\text { The learning object generator will save } \\
\text { teachers' efforts. }\end{array}$ & $3 \%$ & $4 \%$ & $3 \%$ & $67 \%$ & $23 \%$ & 4.42 & 1.01 \\
\hline $\begin{array}{l}\text { Learning objects produced from the generator } \\
\text { will be more effective to students. }\end{array}$ & $5 \%$ & $2 \%$ & $3 \%$ & $49 \%$ & $41 \%$ & 4.22 & 1.04 \\
\hline $\begin{array}{l}\text { The learning object generator will save } \\
\text { teachers' time. }\end{array}$ & $1 \%$ & $1 \%$ & $3 \%$ & $51 \%$ & $44 \%$ & 4.40 & 0.71 \\
\hline $\begin{array}{l}\text { The learning object generator will encourage } \\
\text { teachers to produce quality learning objects }\end{array}$ & $1 \%$ & $4 \%$ & $6 \%$ & $58 \%$ & $31 \%$ & 4.37 & 0.90 \\
\hline $\begin{array}{l}\text { The generator will help teachers improve their } \\
\text { performance. }\end{array}$ & $4 \%$ & $1 \%$ & $5 \%$ & $59 \%$ & $31 \%$ & 4.35 & 1.00 \\
\hline $\begin{array}{l}\text { If available, teachers will use the learning } \\
\text { objects generator }\end{array}$ & $1 \%$ & $1 \%$ & $3 \%$ & $51 \%$ & $44 \%$ & 4.40 & 0.71 \\
\hline $\begin{array}{l}\text { The generator is needed to meet the needs of } \\
\text { the students of information and services } \\
\text { related to their specific curriculum }\end{array}$ & $8 \%$ & $1 \%$ & $4 \%$ & $63 \%$ & $24 \%$ & 4.22 & 1.28 \\
\hline $\begin{array}{l}\text { The generator will enhance teachers, } \\
\text { technological skills. }\end{array}$ & $1 \%$ & $1 \%$ & $3 \%$ & $81 \%$ & $14 \%$ & 4.70 & 0.73 \\
\hline $\begin{array}{l}\text { The generator is needed for enhancing the } \\
\text { trend towards a knowledge-based society }\end{array}$ & $1 \%$ & $7 \%$ & $7 \%$ & $56 \%$ & $29 \%$ & 4.27 & 1.00 \\
\hline $\begin{array}{l}\text { The generator is a tool that helps in reducing } \\
\text { the digital divide }\end{array}$ & $5 \%$ & $3 \%$ & $7 \%$ & $58 \%$ & $27 \%$ & 4.25 & 1.11 \\
\hline $\begin{array}{l}\text { The generator will help to increase the growth } \\
\text { of knowledge to teachers and students }\end{array}$ & $7 \%$ & $7 \%$ & $6 \%$ & $59 \%$ & $21 \%$ & 4.13 & 1.27 \\
\hline $\begin{array}{l}\text { The generator is needed for promoting access } \\
\text { to knowledge related to curriculum. }\end{array}$ & $6 \%$ & $2 \%$ & $7 \%$ & $52 \%$ & $33 \%$ & 4.18 & 1.12 \\
\hline In gener| & & & & & & & \\
\hline
\end{tabular}

In general, the results show that it most teachers $(88.93 \%$, Mean $=4.35)$ agree to establish a learning objects generator to be able to create learning objects by their own. The following is a summary of their replies, as shown in table 1:

95\% agreed about the following: the generator will enhance teachers, technological skills $(\mathrm{M}=4.70)$, it will allow teachers to produce learning objects without the need to have technical skills $(\mathrm{M}=4.66)$, it will save teachers' time $(\mathrm{M}=4.40)$, and if it is available, they will use it $(\mathrm{M}=4.40)$. while $90 \%$ of teachers reported that the learning object generator will save teachers' efforts $(\mathrm{M}=4.42)$ and learning objects produced from the generator will be more effective to students $(\mathrm{M}=4.22)$. Moreover, they believe that the generator will help them improve their performance $(\mathrm{M}=4.35)$.

Also, $89 \%(\mathrm{M}=4.37)$ of the teachers reported that the learning object generator will encourage them to produce quality learning objects, $88 \%(\mathrm{M}=4.46)$ stated that the generator will allow to produce learning objects addressing the curriculum, and $87 \%(\mathrm{M}=4.22)$ agreed that the generator is needed to meet the needs of the students of information and services related to their specific curriculum. 
In addition, 85\% of them agreed about the following: the generator will allow to produce different styles of learning objects to meet the students' needs $(M=4.27)$, it is needed for enhancing the trend towards a knowledge-based society $(M=4.27)$, it is a tool that helps in reducing the digital divide $(M=4.25)$, and it is needed for promoting access to knowledge related to curriculum $(M=4.18)$. Finally, $80 \%(M=4.13)$ of them agreed that the generator will help to increase the growth of knowledge to teachers and students.

Based on the previous results, there are many expected benefits for the Sultanate of Oman from establishing a learning objects generator, these benefits can be described as follows:

- The effective contribution of the Sultanate of Oman in providing a space for sharing and cooperation between Arab countries in the field e-educational content and continuing to play the pioneering and distinguished national and regional role of Oman.

- Development of an Omani digital platform concerned with designing self-produced elearning objects, in the sense of designing learning objects by users (educators, interested persons and other stakeholders) who do not have knowledge and skills in the design and production process and the technical aspects with minimal time and effort.

- Striving towards maximizing the benefit of Omani cadres in the field of designing and developing interactive electronic content and participating in tangible and valuable contributions to the Omani education community.

- Enabling teachers in the Sultanate of Oman to publish lessons, assignments, implement educational activities and share educational content with their students, which helps to achieve high-quality educational outcomes.

- Striving to activate, exchange and share teaching experiences among members of the Omani educational community and the Arab countries and enable teachers to communicate with each other and exchange ideas and opinions through multiple technologies, thus contributing to improving the quality of performance within the education community in the Sultanate of Oman.

- Allowing the opportunities to accommodate institutional and individual initiatives in the field of designing, producing, and making electronic educational content available in the Sultanate of Oman.

- Putting education in the Sultanate of Oman on the Arab and regional map through a platform bearing the Omani character in its knowledge content and in its human cadres in the field of education.

- Keeping pace with the rapid developments in the design, production, and availability of interactive electronic content, and paving the way for a future stage in which e-learning is institutionalized as a parallel or supportive system for learning in its traditional modular form.

The current research project contributed to build a model for digital learning objects in light of global educational and technical standards consistent with the teaching and learning environment in the Sultanate of Oman, and responding to the actual needs of that environment, and accurately reflecting the nature of the educational content at that 
educational stage, the characteristics of the learners in Oman, and the digital infrastructure in Oman. Also, the availability of learning object generator can create and provide real opportunities for international, regional, and local partnerships with governmental and private institutions related to the nature of education and learning in Oman.

Moreover, it will help to maximize the benefit from the Omani cadres in the field of designing and developing interactive electronic content and participating with tangible and valuable contributions to the Omani education community. As well as establishing the concept of free access to educational digital content (digital learning objects) through an Omani educational platform based on standards and principles consistent with the nature and needs of the educational community in Oman.

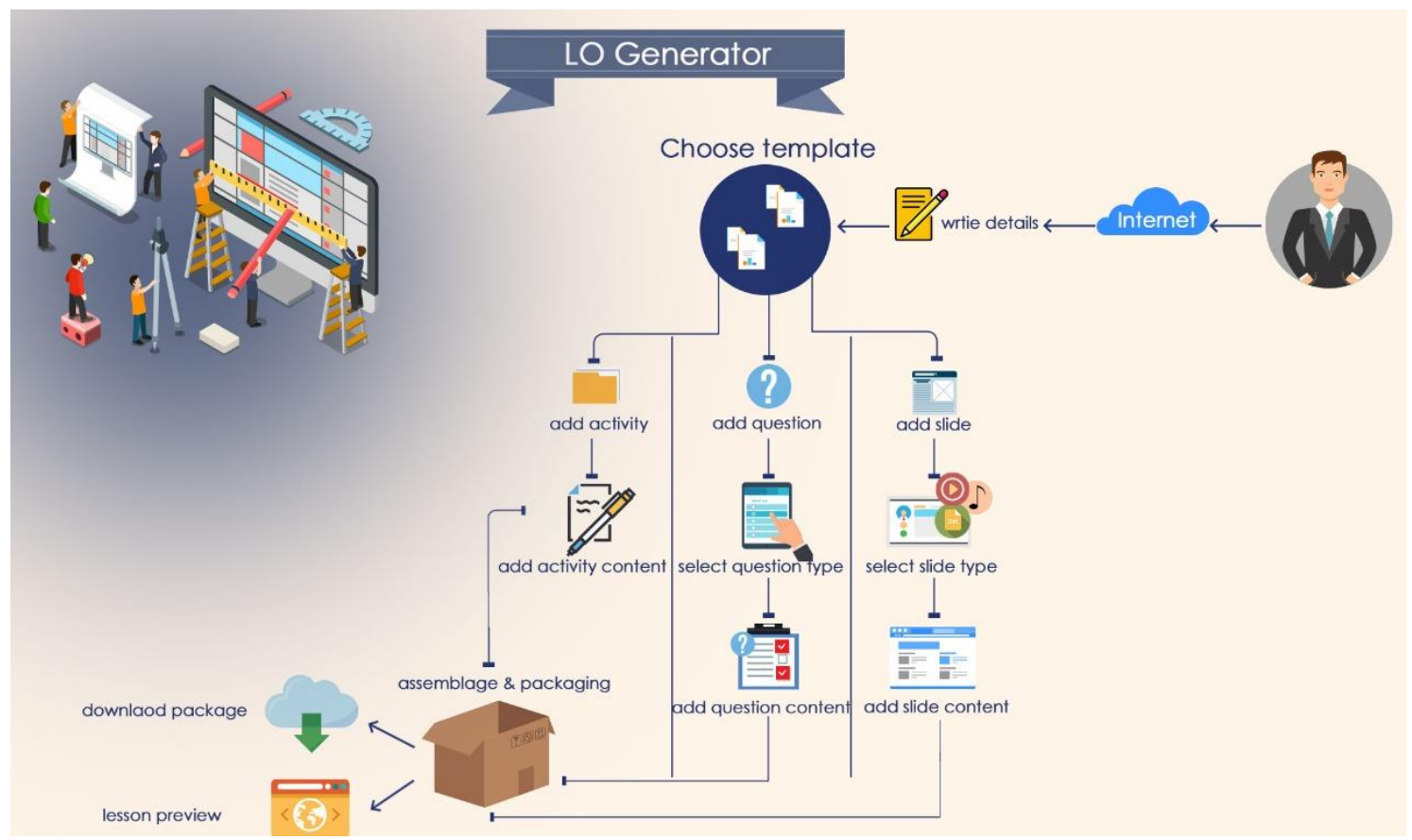

Figure 2 A proposed learning objects generator model

Figure 2 shows a proposed model for establishing a learning objects generator used for producing educational content and storing them. This model is suggesting some features that can help teachers easily use the generator, where the teacher can create his own account and do the following:

- Add educational object data.

- Choose the template for the required learning object.

- Adding different types of content.

- Adding questions to the learning object.

- Exporting learning objects to be used. 


\section{Conclusion}

This research project seeks to develop an Omani platform to make digital knowledge available, which allows learners, interested persons and other stakeholders to design and produce electronic learning objects on their own without any educational or technical requirements or needs, only the teacher introduces the specialized educational content in it with the activities it contains, or evaluations, or auxiliary media for that platform in light of a specific mechanism, so that at the end of the matter and within a very limited time and without any effort that may represent a burden on the user, he will eventually obtain a learning object on its own, this object will be automatically uploaded to the platform until it is available For all registered users of the platform, and the teacher can exploit this object for any other purposes and in any other educational context.

Finally, building digital generator is needed according to the results of the current study.

\section{Acknowledgements}

The research leading to these results has received funding from the Research Council (TRC) of the Sultanate of Oman under the Block Funding Program. TRC Block Funding Agreement No [BFP/RGP/EHR/18/159].

\section{References}

Basuhail, A. A. (2020). Application of Learning Objects for Computer Programming-Based Problem Solving. Canadian Journal of Learning and Technology, 46(1), n1.

Carvalho, H. F. B., Pitangui, C. G., Trindade, E. C., de Assis, L. P., \& Andrade, A. V. (2020, October). Learning objects and youtube: an analysis of videos and their categories. In $2020 \mathrm{XV}$ Conferencia Latinoamericana de Tecnologias de Aprendizaje (LACLO) (pp. 1-6). IEEE.

Goranova, E. (2019). Creation of Electronic Learning Objects for the High Cognitive Levels of Bloom's Digital Taxonomy. KNOWLEDGE-International Journal, 31(2), 585-590.

Hale, J., \& Weaver, K. D. (2021). The Proof is in the Pudding: Building a Local Repository for Online Learning Objects. Association of College \& Research Libraries.

Ho, M., Taylor, M., McSharry, E., Bergmann-Tyacke, I., Santos, M. R., Dhaeze, M., ... \& Konstantinidis, S. T. (2021). The role of stakeholders' evaluation on the quality of reusable learning objects following the ASPIRE participatory framework.

Huba, M., Hypiusová, M., \& Tapák, P. (2019, June). Learning objects and experiments for active disturbance rejection control. In 2019 5th Experiment International Conference (exp. at'19) (pp. 161-166). IEEE.

Martínez-Royert, J. C., Castañeda, Y. C., Carrero-González, C. M., Santander, M. A. O., Ustate, S. S., Arévalo, D. S., ... \& Sierra-Carrero, L. L. (2021). Design and Validation of Virtual Learning Objects to Promote Health in School Students. Linguistica Antverpiensia, 1568-1581.

Martinez-Zambrano, K., Paez, J., \& Florez, H. (2021). Pedagogical model to develop virtual 
learning objects for people with hearing impairment.

Mourão, A. B., \& Netto, J. F. D. M. (2019). Inclusive Model Application Using Accessible Learning Objects to Support the Teaching of Mathematics. Informatics in Education, 18(1), 213-226.

Onofrei, G., \& Ferry, P. (2020). Reusable learning objects: a blended learning tool in teaching computer-aided design to engineering undergraduates. International Journal of Educational Management.

Poultsakis, S., Papadakis, S., Kalogiannakis, M., \& Psycharis, S. (2021). The management of digital learning objects of natural sciences and digital experiment simulation tools by teachers. Advances in Mobile Learning Educational Research, 1(2), 58-71.

Robin Kay and Liesel Knaack (2015). Developing Learning Objects for Secondary School Students: A Multi-Component Model, Interdisciplinary Journal of Knowledge and Learning Objects. Volume 1, 2005.

Rutkauskiene, D., Gudoniene, D., Bartkute, R., \& Volodzkaite, G. (2019). Smart Learning objects for online and blended Learning approach. In Smart Education and e-Learning 2019 (pp. 189199). Springer, Singapore.

Silvia, A. (2015). COURSERA ONLINE COURSE: A PLATFORM FOR ENGLISH TEACHERS' MEANINGFUL AND VIBRANT PROFESSIONAL DEVELOPMENT. TEFLIN Journal, 228-246.

Staikopoulos, A., O'Keeffe, I., Rafter, R., Walsh, E., Yousuf, B., Conlan, O., \& Wade, V. (2014). AMASE: A framework for supporting personalised activity-based learning on the web. Computer Science and Information Systems, 11(1), 343-367. 